II

VARIÁVEIS FONÉTICO-FONOLÓGICAS 



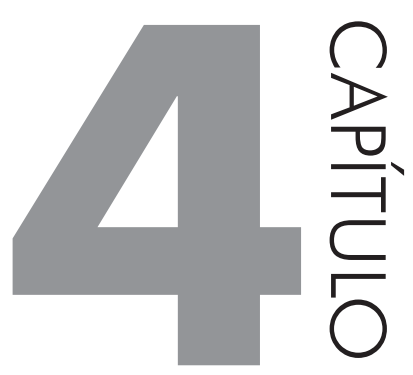

\section{RÓTICOS NAS VARIEDADES URBANAS SANTOMENSE E MOÇAMBICANA DO PORTUGUÊS}

\section{SILVIA FIGUEIREDO BRANDÃO E ALESSANDRA DE PAULA}

\section{INTRODUÇÃO}

Poucos são os estudos que contemplam as variedades africanas do Português, sobretudo no que respeita a aspectos fonético-fonológicos. Dentre as pesquisas já realizadas, a grande maioria versa sobre aspectos morfossintáticos, sintáticos, lexicais, entre outras áreas, como se pode verificar consultando o site $^{1}$ organizado pela Cátedra de Português da Universidade Eduardo Mondlane, de Moçambique. No que toca a São Tomé, entre os 53 trabalhos arrolados, apenas dois (3,7\%) dizem respeito a essa área (SILVEIRA, 2013; SANTOS, 2012). Quanto à Moçambique, dos 494 trabalhos que compõem o acervo, quatro $(0,8 \%)$ versam sobre questões fonológicas (EMBE, 1992; HOMO, 2002; VICENTE, 2009 e 2010).

Embora sejam marcantes alguns traços de pronúncia que distinguem as variedades santomense e moçambicana do Português Europeu, só a partir de 2015 se observa um interesse mais específico em verificar características do sistema

\footnotetext{
1 http: //catedraportugues.uem.mz/?__target__=bibliografia-new
} 
fonológico do Português de São Tomé (PST) e do Português de Moçambique (PM). Nestes três últimos anos, foram divulgados estudos sobre questões prosódicas, o funcionamento do quadro vocálico e os róticos no PST, estes últimos também focalizados no PM.

Dentre esses temas, talvez o mais saliente seja o que concerne aos róticos, não só pela complexidade que caracteriza essa família de sons, mas também por eles apresentarem alto grau de variação no âmbito de diversas línguas e, em particular, nas variedades aqui em foco.

Assim, neste capítulo, tem-se por objetivo analisar os róticos nos contextos pré-vocálico e pós-vocálico nas variedades urbanas do PST e do PM, de acordo com os pressupostos da Teoria da Variação e Mudança (WEINREICH; LABOV; HERZOG, 1968) e nos desdobramentos da Sociolinguística Variacionista (LABOV, 1972, 1994, 2001, 2003), de forma a contribuir não só para o conhecimento dos sistemas fonológicos dessas duas variedades, mas também para depreensão de divergências e convergências entre elas e o PE, que lhes serve de norma de referência.

Desenvolve-se o tema em mais cinco seções. Na segunda, faz-se uma breve caracterização dos róticos e mencionam-se aqueles que ocorrem em variedades do Português; na terceira, indicam-se os procedimentos metodológicos que nortearam as análises. Nas seções 4 e 5, expõem-se, de forma contrastiva, os resultados referentes, respectivamente, aos contextos pré-vocálicos e pós-vocálicos no PST e no PM. Na sexta seção, apresentam-se as considerações finais.

\section{OS RÓTICOS}

Os sons de R, caracterizados como uma família (LINDAU, 1985: 167) e não propriamente como uma classe de sons, stricto sensu, por não apresentarem um traço comum ${ }^{2}$ que os caracterize como tal, são bastante diversificados quanto à sonoridade, ao modo e ao ponto de articulação. Dessa família fazem parte as vibrantes alveolar e uvular, tepes ou flepes alveolar e retroflexo, aproximantes alveolar e retroflexa e as fricativas velar, uvular e glotal, que, não obstante, em diferentes línguas, são representados graficamente por $-r$ ou $-r r$ e se comportam de forma similar quanto à sua distribuição contextual: num sistema fonológico, em que há grupos consonantais, os róticos costumam ocorrer próximos ao núcleo silábico; em posição de coda, tendem à vocalização e ao cancelamento; e frequentemente alternam com outros róticos a depender do contexto.

2 Ladefoged (1975) e Lindau (1978) aventam a hipótese, ainda não confirmada, de ser uma característica acústica (um terceiro formante abaixado) o elemento comum a esse conjunto de fones. 
No Português Europeu, a norma de referência das variedades africanas, na posição intervocálica, a comutação de um R "fraco" por um R “forte”, como se convencionou dizer, pode acarretar distinção significativa (caro x carro). Nesse contexto, no primeiro caso, ocorre o tepe, que também está presente em coda silábica e em grupos consonantais e, no segundo, na fala atual de Lisboa, a vibrante uvular, a mesma que se encontra em início de vocábulo. Segundo Mateus; d'Andrade (2000: 11), este último segmento coocorre com outras variantes recuadas, "sobretudo a fricativa uvular sonora [в] ou a surda $[\chi]$; a vibrante alveolar [r] é comum em outros dialetos que não o aqui em consideração"3 (no caso, o da região de Lisboa).

No PST e no PM não há, na fala de muitos indivíduos, o mesmo tipo de distribuição de segmentos que se verifica no Português Europeu (PE) e no Português do Brasil (PB). Em alguns casos, a neutralização entre o rótico [+ant] e o [-ant] se dá também no contexto intervocálico, em que tanto pode ocorrer um tepe quanto uma vibrante alveolar (ou uma fricativa uvular, no caso do PST), anulando distinções do tipo caro x carro. Tal variação também está presente no contexto inicial de vocábulo ([r]oça/[r]oça), em que, no PE atual, se esperaria, por exemplo, a vibrante uvular ou a vibrante alveolar (a pronúncia mais conservadora) ou, ainda, uma fricativa.

Embora seja a língua oficial em ambos os países, a situação do Português é diferente quanto à sua representatividade: enquanto, em São Tomé, é atualmente falado por $98,4 \%$ da população, predominantemente com L1, em Moçambique, apenas cerca de $10 \%$ dos habitantes o têm como L1 e 42,9\%, como L2. No entanto, no que se refere à variabilidade dos róticos, há significativos pontos de contato entre as duas variedades, o que levou à formulação da hipótese da possível interferência de outras línguas faladas nessas duas áreas, que se caracterizam pelo alto grau de contato multilinguístico.

Em São Tomé e Príncipe, o Forro ou Santome, considerado a "língua nacional", é o crioulo mais difundido na capital, tendo gozado de certo prestígio até a época da independência (1975), o que levava indivíduos de outras etnias a aprendê-lo (MAURER, 1995: 1). Antes falado por $72,4 \%$ da população, segundo o Censo de 2001, e hoje reduzido a apenas 36,3\% de falantes, o Forro ainda coexiste com o Angolar, na Ilha de São Tomé; o Lung'ie (ou Principense) na Ilha do Príncipe, com o português dos Tongas e o Cabo-verdeano (crioulo de base portuguesa, nativo de Cabo Verde) e "resquícios de línguas do grupo Banto" (HAGEMEIJER, 2009), todos com um número bastante reduzido de utentes.

3 "[...] namely the voiced uvular fricative $[$ ь $]$ or the voiceless one $[\chi]$; the alveolar trill $[\mathrm{r}]$ is common in dialects other than the one under consideration". 
O Forro, ao que tudo indica, não tem em sua gênese nenhum rótico: quando da formação desse crioulo, os róticos dos itens lexicais do Português a ele incorporados foram reinterpretados como lateral alveolar - faluza (ferrugem), ficicelo (feiticeiro) - ou apagados - soci (sorte), segundo Ferraz (1979: 22-23). Só muito recentemente, itens lexicais com róticos passaram a constituir o léxico do Forro.

Quanto ao PM, em que os róticos se comportam de forma similar à do PST e o Português coexiste com cerca de 26 línguas do grupo Banto, as únicas menções à variação nessa variedade, anteriores aos estudos de Brandão; de Paula (2017a, 2017b, 2017c), encontram-se em Dias (2009, p. 405, apud TIMBANE; BERLINCK, 2012: 218) - "no PM há troca entre as consoantes vibrantes simples e múltiplas" - e em Gonçalves (2010: 42), que observa que entre os falantes de L1 Changana, a língua que predomina em Maputo,

cujo sistema fonológico possui apenas a vibrante dupla [R] e não tem uma vibrante simples [r] (Sitoe e Ngunga, 2000) pode acontecer que, em palavras do PE como areia ou herói, o [r] seja pronunciado como [R], verificando-se que, provavelmente por um fenômeno de hipercorreção, em palavras como carro e morrer, o $[\mathrm{R}]$ seja pronunciado como $[\mathrm{r}]$.

$\mathrm{Na}$ gramática do Changana mencionada por Gonçalves (NGUNGA; SIMBINI, 2012), entre os 22 fonemas expostos no quadro das consoantes (p. 29), aparece a "vibrante múltipla alveolar com ar pulmonar expirado. Ex.: kurila 'chorar'; rito 'voz'; murimi 'camponês'”. Mais adiante (p. 41), diz-se que

o som representado por $\mathbf{r}$ é vibrante, pois na sua produção a ponta da língua bate de forma intermitente na região alveolar o que dá sensação de vibração, como nos seguintes exemplos: 20. murimi 'agricultor', kuringa 'provar', lirimi 'língua,

não havendo nenhuma outra observação sobre esse segmento, que, pelo que se afirma quanto à estrutura da sílaba (p. 67), não deve ocorrer em coda:

como se vê, em Changana, quando a sílaba compreende mais do que um fonema, todos os elementos não silábicos ocorrem na margem esquerda (portanto, nunca na margem direita) e é obrigatória a presença de uma vogal que é o elemento mais proeminente da sílaba.

Se, quanto ao PM e às línguas com ele em contato, há apenas notas esparsas a respeito do comportamento dos róticos, no que tange, atualmente, ao PST, como se mencionou na introdução deste capítulo, já existem uns poucos estudos. Brandão et al. (2017, no prelo, p. 198-199) observam que 
Entre 2015 e 2016, diferentes pesquisadores focalizaram os róticos no PST. No VI Encontro do Grupo de Estudos de Línguas em Contato, realizado na Universidade Federal da Bahia, Brandão; Vieira (2015) já mencionavam a variação existente nos diferentes contextos de ocorrência de R, o que também ocorreu (Brandão 2016b) durante o Encontro Anual da Associação de Crioulos de Base Lexical Portuguesa e Espanhola (ACBLPE), realizado em Cabo Verde (junho de 2016). Neste último Encontro, Bouchard (2016) informou que, na variedade emergente do PST, em variação com o tepe e com outras variantes, se produziria a fricativa uvular [b] em contextos como [рьоfе'sове], [бьаzi'leјье], isto é, em ataque complexo e em posição intervocálica, mudança que estaria ocorrendo entre os falantes jovens da classe média "who are pride of their Santomean identity", o que se verifica também na amostra aqui considerada, embora com uma frequência ainda baixa. Ainda em 2016, durante IX Encontro da ABECS, realizado em Brasília, na mesma sessão de trabalho, Brandão (2016c) reiterou a neutralização entre os róticos em qualquer posição e Agostinho (2016) tratou dos róticos em contexto intervocálico na fala da Ilha de Príncipe, com destaque sobretudo aos contextos também focalizados por Bouchard na sua comunicação. Acrescente-se que os róticos foram o tema da tese de Bouchard (2017).

Neste estudo, para fins de comparação e complementação da análise a ser desenvolvida no item 4, destacam-se algumas observações de Bouchard (2017), tese desenvolvida na perspectiva sociolinguística, mas caracterizada pela autora também como de natureza etnográfica.

Bouchard trata dos róticos e da expressão do pronome sujeito no PST para "discutir a emergência dessa variedade do Português por meio da compreensão de fenômenos sociais e ideológicos que explicam a variação e a mudança” (p. 294). Quanto aos róticos, seu principal objetivo é verificar, nos diferentes contextos em que eles podem ocorrer, a difusão das variantes "fortes", sobretudo as fricativas, o que ela considera um símbolo de "santomensidade", isto é, um traço que distinguiria o PST das demais variedades do Português, mudança que estaria sendo implementada pelos mais jovens. Para tanto, ela se vale do Programa R e de 6.720 dados da fala de 56 informantes (120 de cada um deles), distribuídos por sexo, cinco faixas etárias (12-18, 20-29, 30-39, 40-49 e 50 ou mais), nível de escolaridade e etinicidade.

$\mathrm{Na}$ sua amostra, ela registrou, conforme a Tabela 7.5 de sua tese (p. 254), $18,5 \%$ de fricativas (uvular, velar, glotal), 55,3\% de tepes alveolares, 4,9\% de vibrantes (alveolar, uvular) e $21 \%$ de cancelamento. Para fins de análise, considerou duas categorias (p. 245): $\mathrm{R}$ forte (fricativas e vibrantes) e $\mathrm{R}$ fraco (tepe e cancelamento de r).

Sua análise teve como focos principais os processos de apagamento de (-r), o uso do R forte e a emergência das fricativas róticas. Quanto ao primeiro processo, 
conclui que o apagamento de $\mathrm{R}$ é implementado na fala dos menos escolarizados e em coda externa, sobretudo em verbos no infinitivo. Quanto aos dois outros processos, em suas conclusões afirma ${ }^{4}$ que

os resultados mostraram que os santomenses usam $\mathrm{R}$ forte em posições não padrão, e que esse uso distinto é uma mudança em progresso claramente liderada pelas gerações mais jovens. Os resultados também indicaram que o uso do $\mathrm{r}$ fraco em posições não padrão é possível, refletindo uma fusão parcial entre o r fraco e o R forte. Finalmente, a fricativa emergente, que é uma alternativa à tradicional vibrante, marca a diferença entre os santomense nascidos antes e depois da independência do país (p. 297).

A análise de Bouchard não focalizou isoladamente cada contexto em que o $\mathrm{R}$ é suscetível de aparecer: ela levou em conta a posição no vocábulo como uma variável independente, analisada em conjunto com as demais variáveis, diferentemente da metodologia empregada nas análises desenvolvidas nos itens 4 e 5 deste estudo, em que as variantes fricativas ocorrem ainda de forma incipiente. Tal procedimento analítico, aparentemente motivado pelo principal objetivo de sua pesquisa (a emergência das fricativas), não permite observar em detalhe a distribuição e os condicionamentos que presidem ao uso das variantes pelos diferentes contextos, mas constitui uma importante contribuição para compreender por que Hagemeijer (2009: 20), entre outros, afirma que "face à situação linguística de S. Tomé e Príncipe, este será o único país da África de língua portuguesa onde a maioria da população tem actualmente o Português como primeira língua, havendo, assim, condições para a emergência de uma nova variedade".

\section{CORPUS E PROCEDIMENTOS METODOLÓGICOS}

A análise dos róticos, realizada com apoio no Programa GOLDVARB-X, levou em conta amostras selecionadas dos corpora mencionados na Apresentação do livro. Todos os informantes representativos de ambas as variedades foram distribuídos por sexo, três faixas etárias (18-35 anos, 36-55 anos e 56 a 75 anos) e três níveis de escolaridade (fundamental: 5 a 8 anos; médio: 9 a 11 anos; superior). Além dessas variáveis sociais, foram consideradas, (a) para São Tomé, a variável frequência de uso do Forro, com o objetivo de aquilatar se o não uso do Forro ou seu uso em maior ou menor grau influenciaria a performance dos indivíduos; (b) para Moçambique, o estatuto do Português (L1 ou L2), bem como o grau de conhecimento/uso de outra(s) língua(s) falada(s) no país. Quanto às variáveis estruturais controlaram-se, a depender do contexto, o modo e o ponto de

4 Esta e as demais traduções são de responsabilidade das autoras deste capítulo. 
articulação das consoantes antecedente e/ou subsequente, a natureza da vogal antecedente e/ou subsequente, a classe do vocábulo, a tonicidade e o número de sílabas, bem como a classe do vocábulo.

$\mathrm{Na}$ seleção dos dados, levaram-se em conta os 25 minutos iniciais das entrevistas no caso do $\mathrm{R}$ em coda externa e interna e a duração total no que respeita ao $\mathrm{R}$ em onset, tendo em vista a sua baixa produtividade neste contexto.

$\mathrm{Na}$ análise comparativa, utilizou-se um total de oito amostras, quatro por variedade e referentes (a) ao chamado " $\mathrm{R}$ forte" em contexto de onset (i) inicial de vocábulo (roça) e (ii) intervocálico (carro); e (b) ao R em coda externa (comer, flor) e interna (carne).

\section{4. $\mathrm{R}$ "FORTE" EM CONTEXTO DE ONSET}

Em função dos objetivos desta análise, apresentam-se os seus principais resultados de forma contrastiva, de modo a melhor aquilatar as convergências e divergências entre as duas variedades aqui focalizadas.

Em contexto de onset inicial de vocábulo, contabilizou-se um total de 564 ocorrências de R para o PST e 752 para o PM; já no intervocálico, computou-se um total de 293 ocorrências para o PST e 529 para o PM.

Como se verifica nas Figuras 1a e 1b, em ambas as variedades, em início de vocábulo, o tepe predomina (PST: 59\%; PM: 53\%), enquanto no intervocálico se observa maior frequência da vibrante alveolar (35\% no PST; $50,5 \%$ no PM), com diferença pouco significativa, mas que parece indicativa de que nem todos os indivíduos têm consciência da oposição fonológica como se verifica no PE e no PB. $\mathrm{O}$ que parece diferenciar as duas variedades é o maior percentual de variantes [-ant] no PST, entre as quais se destaca a fricativa uvular sonora [в].

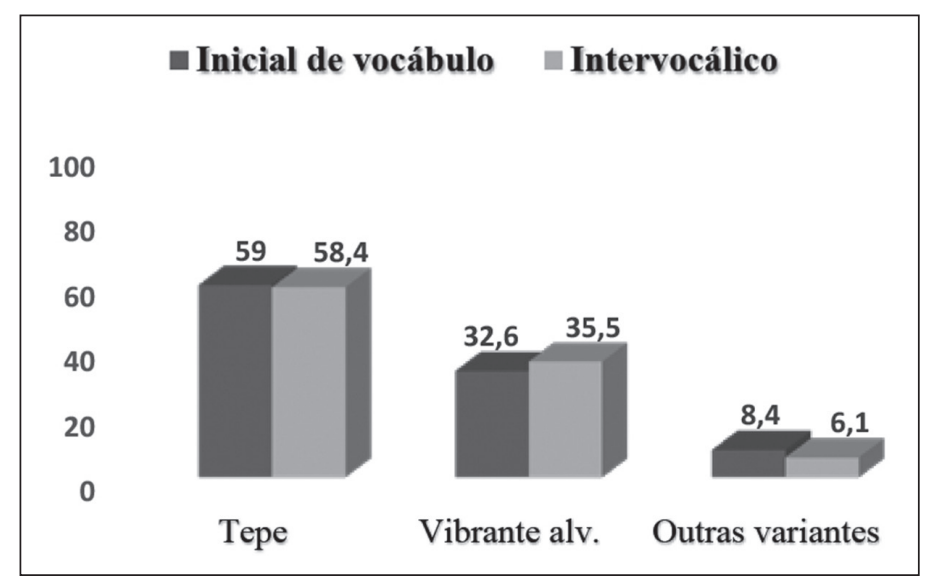

Figura 1a Variantes de R forte em contexto pré-vocálico no PST (percentuais) 


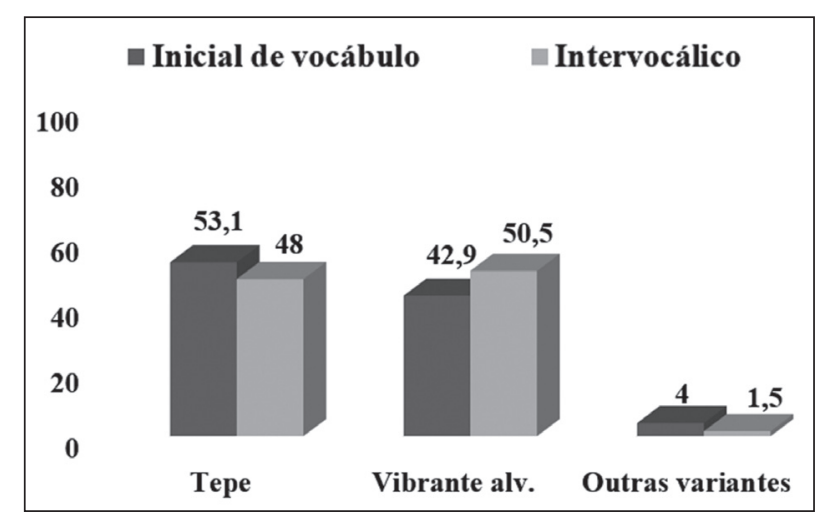

Figura $\mathbf{1 b}^{5}$ Variantes de R forte em contexto pré-vocálico no PM (percentuais)

Tendo em vista que o tepe não é a variante esperada no PE e no PB padrão, as análises do $\mathrm{R}$ em onset terão como valor de aplicação esse fone em contraposição à vibrante alveolar, no sentido de verificar os condicionamentos que presidem à sua implementação, como se verá nos dois subitens a seguir.

\subsection{Inicial de vocábulo}

Em contexto inicial de vocábulo, tanto no PST quanto no PM, foram selecionadas as mesmas variáveis (cf. Figuras $2 \mathrm{a}$ e $2 \mathrm{~b}$ ) como salientes para a implementação do tepe, embora com diferentes relevância e input: .63 no PST e .56 no PM. $\mathrm{Na}$ primeira das citadas variedades, faixa etária e nível de escolaridade têm proeminência sobre a tonicidade da sílaba, enquanto, na segunda, nível de escolaridade e tonicidade da sílaba parecem exercer maior influência que a faixa etária. Apesar disso, em ambas as variedades, a sílaba pretônica (PST: 62,8\%, P. R.: .55; PM: $61,3 \%$, P. R.: .57) parece ser a mais suscetível ao tepe, com índices percentuais e pesos relativos bem semelhantes.

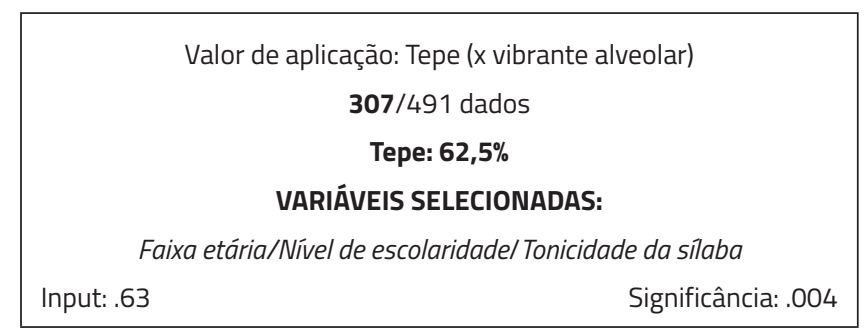

Figura 2a R inicial de vocábulo no PST

5 Algumas das figuras e tabelas referentes à variedade do PST têm como fonte Brandão et al. (2017) e as referentes à variedade do PM, Brandão; de Paula (2017a, 2017b e 2017c). 


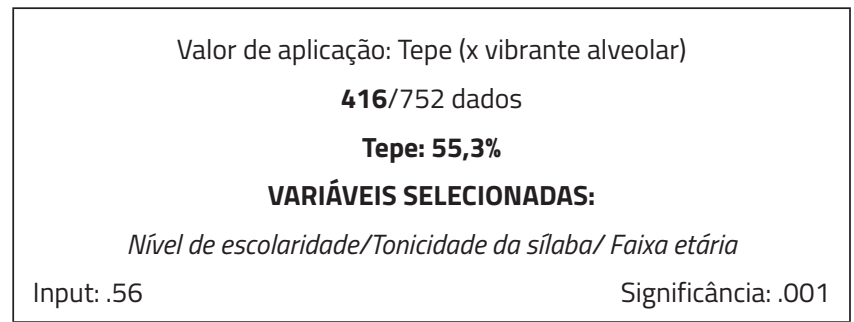

Figura 2b R inicial de vocábulo no PM

No que concerne à atuação da faixa etária e do nível de escolaridade, a observação dos primeiros resultados levou a procedimentos metodológicos diferentes na análise final de cada variedade. Na do PST, amalgamaram-se as duas variáveis (Figura 3), enquanto na do PM elas foram consideradas separadamente. (Figuras 4 e 5 ).

De acordo com o exposto na Figura 3, os indivíduos de nível médio de instrução têm comportamento diferenciado dos de nível fundamental e superior. Nos destas duas últimas classes, observa-se um movimento escalar, em que os mais jovens apresentam os maiores índices de uso do tepe (fundamental: P. R.: .75; superior: .44), enquanto os mais velhos detêm as menores taxas (fundamental: P. R.: .08; superior: P. R.: .11). Cabe ressaltar, ainda, que o range que separa os mais jovens dos mais velhos, no nível fundamental, é de .67, e no nível superior, de .33, o que parece demonstrar que os falantes deste último nível, que, em geral fizeram sua formação superior em Portugal, aproximam-se da norma europeia.

Já entre os indivíduos de nível médio, detecta-se um quadro de variação estável, em que os falantes da faixa etária intermediária apresentam os maiores índices de uso do tepe (P. R.: .79), bem como os das faixas extremas dos outros dois níveis.

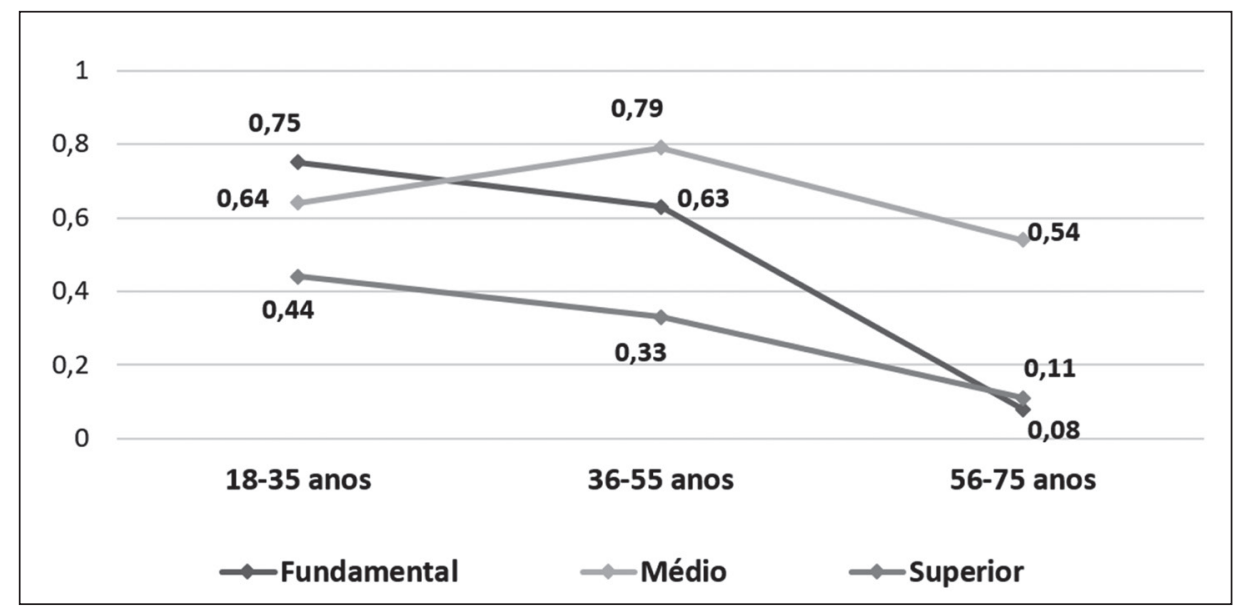

Figura 3 Tepe em contexto inicial de vocábulo no PST - faixa etária/nível de escolaridade 
No PM, detecta-se a mesma escalaridade quanto ao nível de escolaridade (Figura 4), também com os indivíduos de nível superior apresentando o menor índice (P. R.: .25) de uso do tepe, provavelmente pelo mesmo motivo indicado para o PST. Nesta variedade, a variação é estável, sendo os indivíduos de nível médio os que menos utilizam essa variante (P. R.: .38).

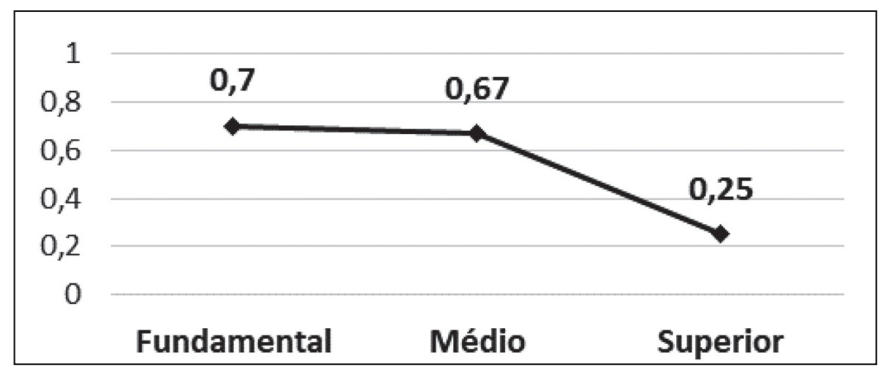

Figura 4 Tepe em contexto inicial de vocábulo no PM - nível de escolaridade

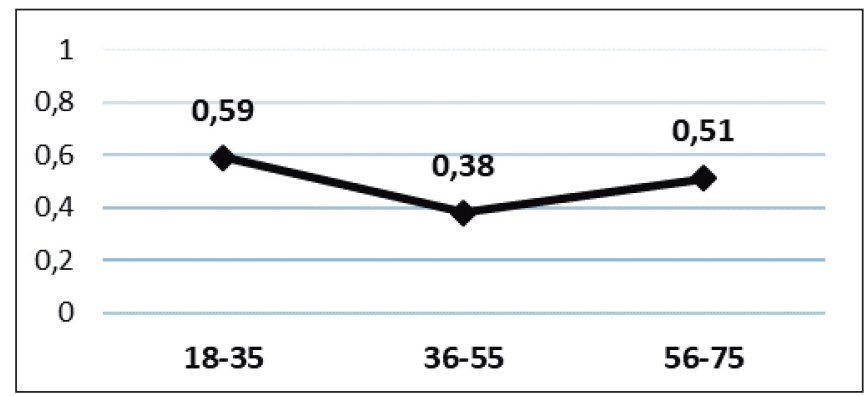

Figura 5 Tepe em contexto inicial de vocábulo no PM - faixa etária

\subsection{Intervocálico}

Em contexto intervocálico, aquele em que o chamado R "forte" é menos produtivo, o PST apresenta um maior número de variáveis atuando para a implementação do tepe, embora a faixa etária e o nível de escolaridade tenham sido selecionados em ambas as amostras.

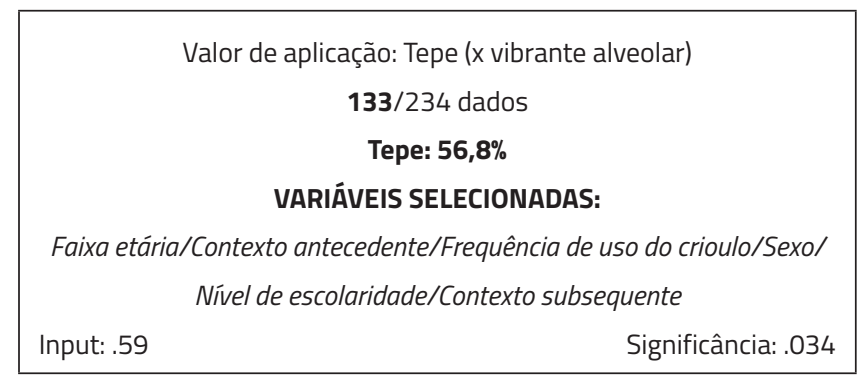

Figura 6a R intervocálico no PST 


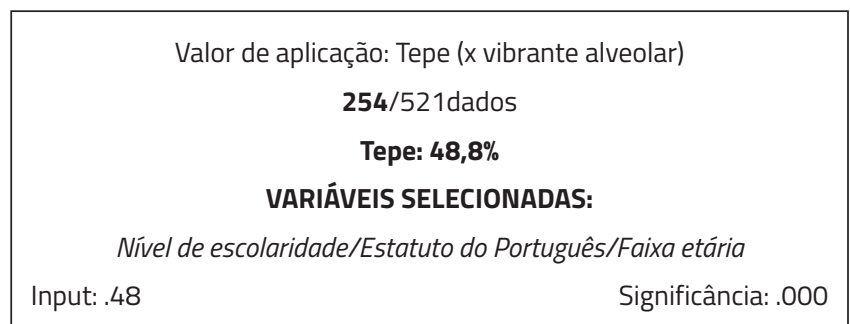

Figura 6b R intervocálico no PM

No PM (Figura 6b), mostraram-se relevantes apenas restrições sociais, enquanto, no PST (Figura 6a), das seis variáveis selecionadas, apenas duas são de natureza estrutural. $\mathrm{O}$ tepe se aplica preferencialmente quando ocorrem vogais [-arr], todas com P. R. acima de .50, sendo as [-rec] - [e $\varepsilon$ i] - em contexto antecedente e a $[+\mathrm{rec}]-[\mathrm{a}]$ - no subsequente, respectivamente, com P. R.: .59 e .72, as mais proeminentes, como se observa na Figura 7.

\begin{tabular}{|c|c|c|c|c|c|}
\hline VARIÁVEL & FATORES & APL./N & $\%$ & P. R. & EXEMPLO \\
\hline \multirow{3}{*}{ Vogal antecedente } & {$[-a r r][+r e c]$} & $30 / 52$ & 57.7 & .52 & ca[r] ego <carrego> \\
\hline & [-arr] [-rec] & $42 / 55$ & 76.4 & .59 & te[r]a <terra > \\
\hline & {$[+$ arr $][+r e c]$} & $54 / 118$ & 45.8 & .44 & $\mathrm{mo}[\mathrm{r}] \mathrm{er}$ <morrer> \\
\hline \multirow{3}{*}{ Vogal subsequente } & [-arr] [+rec] & $45 / 61$ & 78.3 & .72 & se $[r] \mathbf{a}<$ serra $>$ \\
\hline & [-arr] [-rec] & $51 / 81$ & 63 & .64 & mo[r]ido <morrido > \\
\hline & {$[+$ arr $][+$ rec $]$} & $36 / 89$ & 40.4 & .22 & co[r]upção <corrupção> \\
\hline \multicolumn{2}{|l|}{ Input: .59 } & & & & Significância: .034 \\
\hline
\end{tabular}

Figura 7 Tepe em contexto intervocálico: atuação dos contextos antecedente e subsequente no PST

No que toca às variáveis sociais, apresentam-se, de início (Figuras 8a e 8b), comparativamente, aquelas que atuaram em ambas as variedades, embora, no que se refere à faixa etária, os procedimentos metodológicos tenham sido diferentes, tendo em vista que, no PST, os indivíduos mais jovens apresentaram o mesmo tipo de performance, o que determinou o amalgamento das duas faixas mais baixas.

Em ambas as amostras, os indivíduos mais velhos mostraram, claramente, menor predisposição ao uso do tepe (PST: P. R.: .22; PM: P. R.: .39) em contraposição aos mais jovens (P. R.: .63). No PM, verifica-se, com um range de apenas .10, uma diferença entre os mais jovens (P. R.: .64) e os da faixa intermediária (P. R.: .54), o que, de certa forma, indica que, em ambas as variedades, são os mais jovens que adotam o tepe. 


\begin{tabular}{|c|c|c|c|}
\hline FATORES & APL./No & $\%$ & P. R. \\
\hline $\begin{array}{c}18-55 \text { anos } \\
\text { (mais jovens) }\end{array}$ & $111 / 160$ & 69.4 & .63 \\
\hline $\begin{array}{c}56-75 \text { anos } \\
\text { (mais velhos) }\end{array}$ & $22 / 74$ & 29.7 & .22 \\
\hline Input: .59 & \multicolumn{2}{|c|}{ Significância: .039 } \\
\hline
\end{tabular}

Figura 8a Tepe em contexto intervocálico: atuação da variável faixa etária no PST

\begin{tabular}{|c|c|c|c|}
\hline FATORES & APL./Nº & PERC. & P. R. \\
\hline $18-35$ anos & $89 / 136$ & 64,4 &. $\mathbf{6 4}$ \\
\hline $36-55$ anos & $66 / 148$ & 44,6 & .54 \\
\hline $56-75$ anos & $99 / 237$ & 41,8 & .39 \\
\hline Input: .48 & \multicolumn{3}{|c|}{ Significância: .000 } \\
\hline
\end{tabular}

Figura 8b Tepe em contexto intervocálico: atuação da variável faixa etária no PM

A variável nível de escolaridade foi selecionada em quinto lugar na análise do PST e em primeiro, na do PM. Na variedade santomense (Tabela 9a), tanto os indivíduos de nível fundamental (P. R.: .40) quanto os de nível superior (P. R.: .25) fazem pouco uso do tepe se comparados aos de nível médio (P. R.: .65). Já na moçambicana, de forma escalar, quanto menos escolarizado o indivíduo mais ele usa o tepe (Fundamental: P. R.: .67; Superior: P. R.: .30).

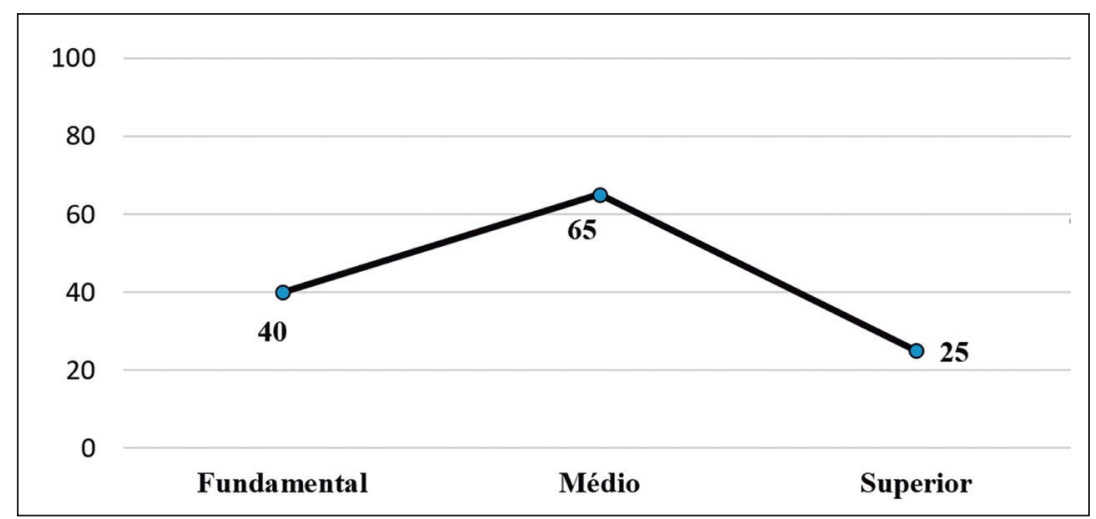

Figura 9a Tepe em contexto intervocálico no PST 


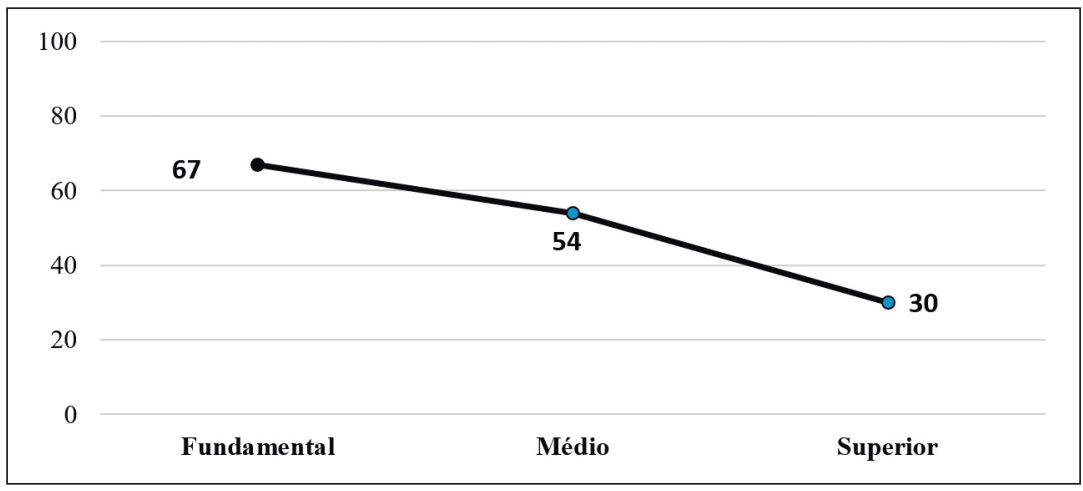

Figura 9b Tepe em contexto intervocálico no PM

Dentre as demais variáveis selecionadas, comentam-se, a seguir, duas outras variáveis sociais, a frequência de uso do Forro em relação ao PST e o estatuto do Português, no que tange ao PM. Ambas as variáveis buscam testar se o uso ou não de outra língua pode condicionar a escolha das variantes. Em São Tomé (Figura 10), os indivíduos que se expressam em Forro com alta ou média frequência (P. R.: .68) tendem a usar mais o tepe, da mesma forma que, em Maputo (Figura 11), aqueles que têm o Português como L2 (P. R.: .73), índices que parecem confirmar a hipótese.

\begin{tabular}{|c|c|c|c|}
\hline & APL/OCO & $\%$ & P. R. \\
\hline Baixa & $72 / 148$ & 48,6 & .39 \\
\hline Média/Alta & $61 / 86$ & 70,9 & .68 \\
\hline
\end{tabular}

Figura 10 Tepe em contexto intervocálico: frequência de uso do crioulo no PST

\begin{tabular}{|c|c|c|c|}
\hline & APL/OCO & $\%$ & P. R. \\
\hline Língua 1 & $150 / 390$ & 38,5 & .41 \\
\hline Língua 2 & $104 / 131$ & 79,4 & .73 \\
\hline
\end{tabular}

Figura 11 Tepe em contexto intervocálico: estatuto do Português no PM

\section{R EM CONTEXTO DE CODA}

Em coda externa, levaram-se em conta 1592 dados para o PST e 2375 para o PM, observando-se, em ambas as variedades, o predomínio do tepe sobre as demais variantes $(77,4 \%$ no PST e $87,3 \%$ no PM), sendo o cancelamento a segunda mais frequente $(44,7 \%$ no PST e $23,5 \%$ no PM). As demais ocorrências, em 
índices muito baixos (na faixa de 1\%), distribuem-se pela vibrante alveolar e variantes [-ant].

Para a análise da coda interna, consideraram-se 1140 ocorrências de R no PST e 1317 no PM, dados que equivalem, em sua maioria, à realização do rótico $(88,8 \%$ no PST e $95,6 \%$ no PM), uma vez que o cancelamento se mostrou muito pouco produtivo neste contexto. Este total, à semelhança do contexto de coda externa, apresenta poucos casos de variantes de $\mathrm{R}$ diferentes do tepe $(6,4 \%$ de vibrante alveolar e $5 \%$ de outras variantes no PST; e 7,3\% de vibrante alveolar e de outras variantes $1 \%$ no PM).

Nas Figuras 12a e 12b, a seguir, expõe-se a distribuição geral das variantes nos contextos de coda nas duas amostras:

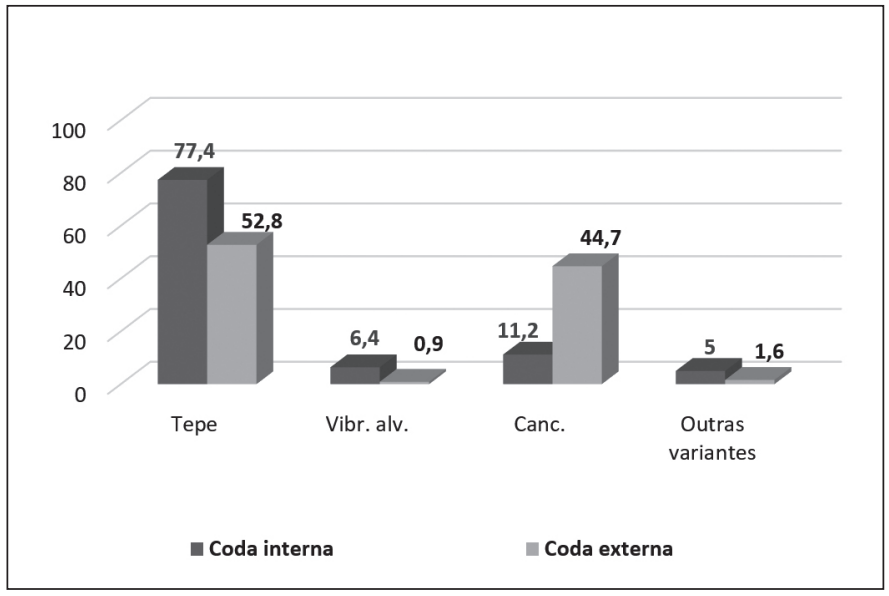

Figura 12a Variantes de R em coda no PST (\%)

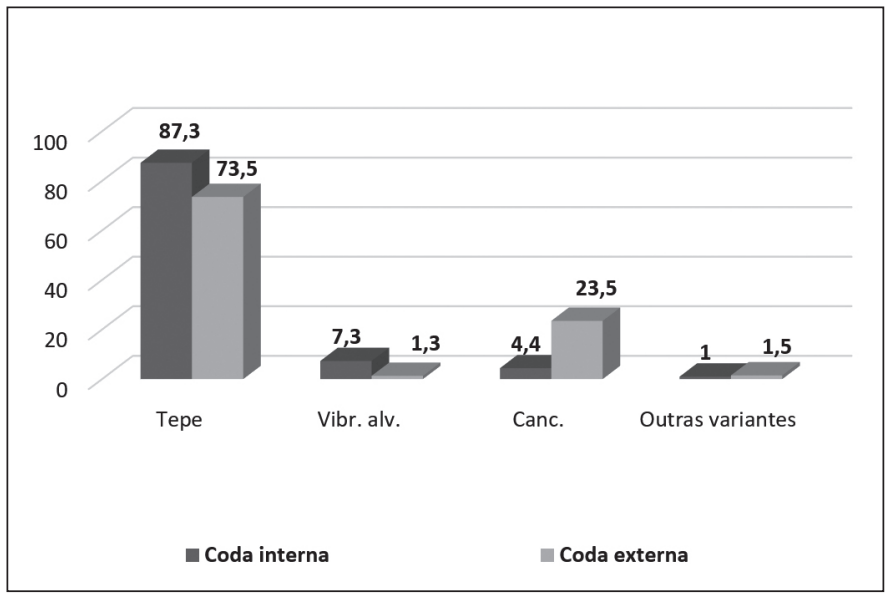

Figura 12b Variantes de R em coda no PM (\%) 
Observa-se a produtividade um pouco maior do cancelamento entre os santomenses, tanto na coda interna quanto na coda externa. Também há, no PST, percentuais um pouco maiores de outras variantes além do tepe. De qualquer forma, considerando-se a baixa frequência desses outros segmentos em ambas as variedades, na análise, o cancelamento foi tomado como valor de aplicação e confrontado com todas as variantes, as quais foram amalgamadas no fator concretização.

\subsection{Coda externa}

Como se confirma nas Figuras 13a e 13b, no PST o cancelamento está mais difundido do que no PM, sendo, não obstante, em ambos os casos, diversas as variáveis que concorrem para a implementação do processo. Foram selecionadas tanto variáveis sociais (nivel de escolaridade e faixa etária no PST e no PM; sexo só no PST) quanto estruturais, dentre as quais o contexto subsequente em ambas as variedades.

\begin{tabular}{|c|c|}
\hline \multicolumn{2}{|c|}{ Valor de aplicação: } \\
\hline \multicolumn{2}{|c|}{ Cancelamento (x concretização) } \\
\hline \multicolumn{2}{|c|}{ 712/1592 dados } \\
\hline \multicolumn{2}{|c|}{ Cancelamento: $44,7 \%$} \\
\hline \multicolumn{2}{|c|}{ VARIÁVEIS SELECIONADAS: } \\
\hline \multicolumn{2}{|c|}{ Nivel de escolaridade/Classe do vocábulo/Contexto subsequentel } \\
\hline \multicolumn{2}{|c|}{ Sexo/Faixa etária } \\
\hline Input: .43 & Significância: .000 \\
\hline
\end{tabular}

Figura 13a R em coda externa no PST: índices gerais e variáveis selecionadas

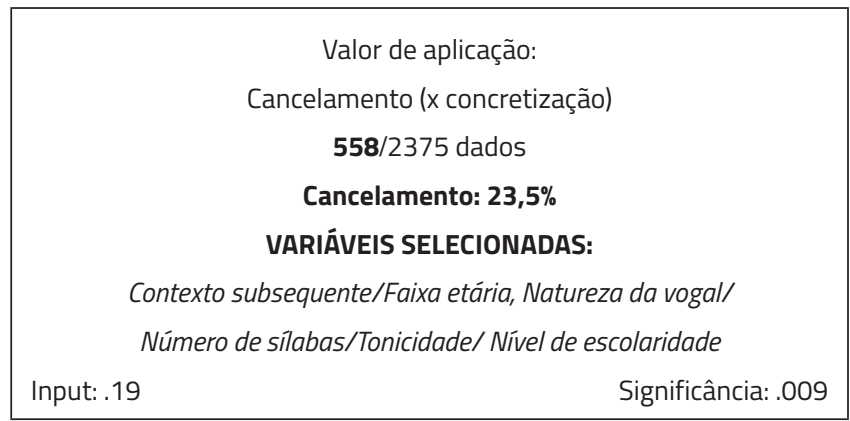

Figura 13b R em coda externa no PM: índices gerais e variáveis selecionadas

Nas duas Figuras seguintes (14 e 15), sintetizam-se os índices obtidos para os fatores de cada variável. 


\begin{tabular}{|c|c|c|c|c|}
\hline VARIÁVEL & FATORES & APL./N\% & $\%$ & P. R. \\
\hline \multirow{3}{*}{ Nível de Escolaridade } & Fundamental & $465 / 586$ & 79,4 & .83 \\
\hline & Médio & $149 / 590$ & 25,3 & .29 \\
\hline & Superior & $98 / 416$ & 23,6 & .25 \\
\hline \multirow{3}{*}{ Classe do vocábulo } & Nome & $36 / 207$ & 17,4 & .14 \\
\hline & Verbo no infinitivo & $655 / 1339$ & 48,9 & .56 \\
\hline & Outras classes & $20 / 45$ & 44,4 & .47 \\
\hline \multirow{3}{*}{ Contexto subsequente } & Consoante & $415 / 743$ & 55,9 & .65 \\
\hline & Vogal & $162 / 489$ & 33,1 & .35 \\
\hline & Pausa & $129 / 354$ & 36,4 & .36 \\
\hline \multirow{2}{*}{ Sexo } & Masculino & $310 / 886$ & 35 & .41 \\
\hline & Feminino & $402 / 706$ & 56,9 & .60 \\
\hline \multirow{2}{*}{ Faixa etária } & 18-35 anos & $354 / 615$ & 57.6 & 61 \\
\hline & 36-75 anos & $358 / 977$ & 36,6 & .42 \\
\hline Input: .43 & & & \multicolumn{2}{|c|}{ Significância: .00 } \\
\hline
\end{tabular}

Figura 14 Cancelamento em coda externa no PST: fatores condicionadores

\begin{tabular}{|c|c|c|c|c|}
\hline VARIÁVEL & FATORES & $\mathrm{N} \%$ & $\%$ & P. R \\
\hline \multirow{3}{*}{ Contexto subsequente } & Consoante & $407 / 1080$ & 37,7 & .69 \\
\hline & Vogal & $95 / 852$ & 11,2 & .31 \\
\hline & Pausa & $55 / 1813$ & 12,6 & .37 \\
\hline \multirow{3}{*}{ Faixa etária } & 18-35 anos & $254 / 844$ & 30,1 & .59 \\
\hline & 36-55 anos & 208/846 & 24,6 & .52 \\
\hline & $56-75$ anos & $96 / 589$ & 14 & .36 \\
\hline \multirow{2}{*}{ Natureza da vogal } & [+ baixa] & $314 / 1175$ & 26,7 & .54 \\
\hline & [-baixa] & $244 / 1200$ & 20,3 & .46 \\
\hline \multirow{4}{*}{ Número de sílabas } & Uma & $87 / 417$ & 20,9 & .49 \\
\hline & Duas & $351 / 1285$ & 27,3 & .54 \\
\hline & Três & $103 / 525$ & 19,6 & .45 \\
\hline & Quatro ou mais & $17 / 148$ & 11.5 & .33 \\
\hline
\end{tabular}




\begin{tabular}{|l|l|c|c|c|}
\hline \multirow{4}{*}{ Tonicidade da sílaba } & Tônica & $\mathbf{5 5 7 / 2 3 4 1}$ & $\mathbf{2 3 , 8}$ & $\mathbf{. 5 0}$ \\
\cline { 2 - 6 } & Postônica & $1 / 34$ & 2,9 & .11 \\
\hline \multirow{3}{*}{ Nivel de escolaridade } & Fundamental & $\mathbf{2 2 3 / 9 0 3}$ & $\mathbf{2 4 , 7}$ & $\mathbf{. 5 0}$ \\
\cline { 2 - 6 } & Médio & $157 / 764$ & 20,5 & .44 \\
\cline { 2 - 6 } & Superior & $178 / 708$ & $\mathbf{2 5 , 1}$ & $\mathbf{. 5 5}$ \\
\hline \multirow{2}{*}{ Input: .19 } & \multicolumn{2}{|c|}{ Significância: .009 } \\
\hline
\end{tabular}

Figura 15 Cancelamento em coda externa no PM: fatores condicionadores

Levando em conta apenas os grupos de fatores comuns, verifica-se que:

(a) o nível de escolaridade atua diferentemente nas duas amostras: no PST, observa-se uma escalaridade: quanto menos escolarizado o indivíduo, mais ocorre o cancelamento; no PM, tanto os indivíduos de nível fundamental (P. R.: .50) quanto os de nível superior (P. R.: 55) deixam de concretizar o $\mathrm{R}$, embora de forma neutra, o que talvez se deva ao caráter incipiente da regra (input .19) nessa variedade;

(b) a faixa etária parece atuar de forma similar, com os indivíduos mais jovens tendendo mais ao apagamento (18-35 anos, PST: P. R.: .61; PM: P. R.: .59).

(c) no contexto subsequente, a consoante é o elemento favorecedor (PST: P. R.: .65; PM: P. R.: .69), permitindo formular a hipótese de seja nessa posição que se está difundindo o apagamento.

Quanto às demais variáveis, observa-se que o cancelamento é mais produtivo:

(a) no PST, em verbos no infinitivo (P. R.: .56), sendo as mulheres quem mais o implementa (P. R.: .60);

(b) no PM, as vogais [+baixas] em contexto antecedente (P. R.: .54), os dissílabos (P. R.: .54) e as sílabas tônicas (P. R.: .50), embora com índices neutros, são os fatores estruturais que favorecem o processo.

\subsection{Coda interna}

Apresentam-se as considerações sobre o cancelamento em coda interna, ressaltando que os resultados devem ser relativizados tendo em vista o baixíssimo índice de variação. 
As Figuras abaixo demonstram que o cancelamento é pouco frequente nas duas variedades e parece ser diferentemente motivado em cada uma delas.

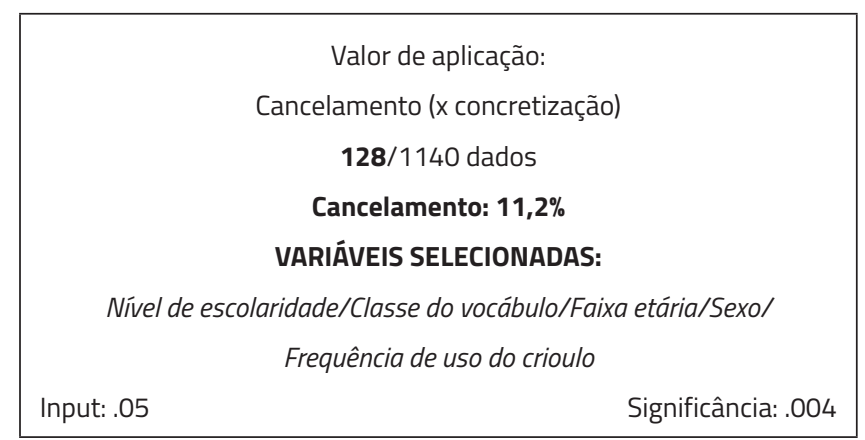

Figura 16a R em coda externa no PST: índices gerais e variáveis selecionadas

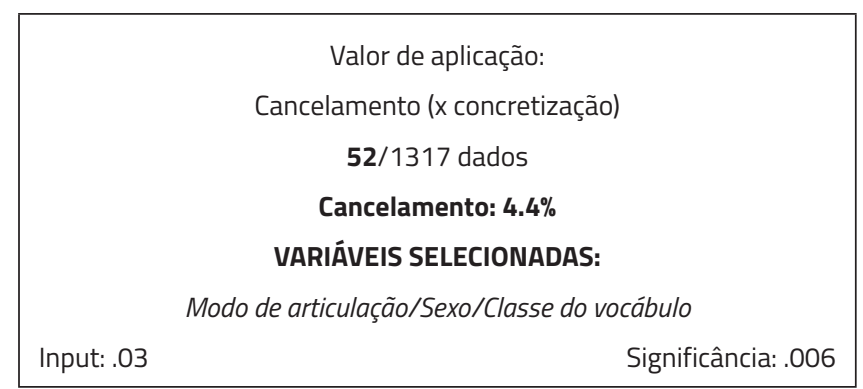

Figura 16b R em coda interna no PM: índices gerais e variáveis selecionadas

Um olhar atento sobre as amostras revela que há pouca diversidade entre os itens lexicais que as constituem, o que pode ter influenciado os resultados da análise estatística. Por exemplo, apesar da seleção da variável classe do vocábulo em ambas as variedades - como se verifica nas Figuras 17 e 18, abaixo -, a presença em grande quantidade das conjunções porque e portanto (itens gramaticais muito frequentes e mais passíveis de redução) na amostra de São Tomé parece estar relacionada com a relevância do fator outras classes, que as inclui. Em Moçambique, em que tais vocábulos não foram considerados na fase de seleção de dados, a classe dos verbos mostrou-se a mais saliente para o cancelamento do rótico, o que pode estar relacionado a outra das variáveis selecionadas: o modo de articulação. Das 22 ocorrências de cancelamento em verbos, 14 ocorrem quando no contexto subsequente há uma consoante [+ cont]: [s] em conversam, conversar (3 ocorrências), exercer, percebo, percebi, perceber (4 ocorrências), proporcionar, [3] em surgiram e [v] em serve. Além disso, em Moçambique, o comportamento idiossincrático de um dos informantes do sexo masculino tornou mais salientes os índices de cancelamento nos resultados finais e pode estar relacionado com a seleção da variável sexo. 


\begin{tabular}{|c|c|c|c|c|}
\hline VARIÁVEL & FATORES & APL./N\% & $\%$ & P. R. \\
\hline \multirow{3}{*}{ Nível de Escolaridade } & Fundamental & $88 / 297$ & 29,6 & .79 \\
\hline & Médio & $28 / 488$ & 5.7 & .40 \\
\hline & Superior & $12 / 355$ & 3,4 & .34 \\
\hline \multirow{3}{*}{ Classe do vocábulo } & Nome & $50 / 725$ & 6,9 & .39 \\
\hline & Verbo no infinitivo & $10 / 143$ & 7 & .44 \\
\hline & Outras classes & $68 / 272$ & 25 & .77 \\
\hline \multirow{3}{*}{ Faixa etária } & 18-35 anos & $65 / 476$ & 13,7 & .55 \\
\hline & $36-55$ anos & $18 / 408$ & 4,4 & .35 \\
\hline & $56-75$ anos & $45 / 256$ & 17,6 & .64 \\
\hline \multirow{2}{*}{ Sexo } & Masculino & $67 / 684$ & 9,8 & .40 \\
\hline & Feminino & $61 / 456$ & 13,4 & .64 \\
\hline \multirow{3}{*}{$\begin{array}{l}\text { Frequência de uso de um } \\
\text { crioulo }\end{array}$} & Zero/Baixa & $49 / 543$ & 9 & .45 \\
\hline & Média & $55 / 551$ & 10 & .51 \\
\hline & Alta & $24 / 46$ & 52,2 & .80 \\
\hline Input: .05 & & & \multicolumn{2}{|c|}{ Significância: .o } \\
\hline
\end{tabular}

Figura 17 Cancelamento em coda interna no PST: fatores condicionadores

\begin{tabular}{|c|c|c|c|c|}
\hline VARIÁVEL & FATORES & APL./N\% & $\%$ & P. R. \\
\hline \multirow{2}{*}{$\begin{array}{l}\text { Modo de } \\
\text { articulação }\end{array}$} & [+ contínua] & $25 / 226$ & 11.1 & .73 \\
\hline & [-contínua] & 33/1091 & 3 & .44 \\
\hline \multirow{2}{*}{ Sexo } & Masculino & 41/684 & 6 & .60 \\
\hline & Feminino & $17 / 633$ & 2.7 & .38 \\
\hline \multirow{3}{*}{$\begin{array}{l}\text { Classe do } \\
\text { vocábulo }\end{array}$} & Nome & 34/988 & 3,4 & .46 \\
\hline & Verbo & $22 / 239$ & 9,2 & .69 \\
\hline & Outras classes & $2 / 90$ & 2.2 & 37 \\
\hline Input: .03 & & & \multicolumn{2}{|c|}{ Significância: .00 } \\
\hline
\end{tabular}

Figura 18 Cancelamento em coda interna no PM: fatores condicionadores 
Assim, a análise multivariada do $\mathrm{R}$ em coda interna é aqui considerada de caráter preliminar, pretendendo-se observá-lo com mais atenção nas próximas etapas da pesquisa, especialmente com um controle mais apurado dos itens lexicais que compõem a amostra.

\section{CONSIDERAÇÕES FINAIS}

Neste capítulo, apresentaram-se, paulatina e comparativamente, os resultados das análises de (i) R "forte" em onset inicial de vocábulo e intervocálico e de (ii) $\mathrm{R}$ em coda externa e interna em duas variedades africanas do Português.

Verificou-se que, em todos os contextos, predomina o tepe, com ele concorrendo a vibrante alveolar nos casos em (i) e o cancelamento em (ii), regras condicionadas sobretudo por fatores de cunho social, salientando-se que, em contexto intervocálico, as variáveis organizadas para controlar questões relacionadas ao contato multilinguístico foram selecionadas: a frequência de uso do Forro, no caso de São Tomé, e o estatuto do Português (L1 ou L2), no caso de Moçambique.

Os resultados sugerem que, tanto no PST quanto no PM, a oposição R [+ant] / R [-ant], em contexto intervocálico não parece fazer parte da gramática muitos dos santomenses e moçambicanos, o que permite formular a hipótese de que haja um único $\mathrm{R}$ no quadro fonológico de ambas as variedades.

A hipótese acima formulada tem respaldo em observações de Lindau (1985). Segundo a autora, "os róticos frequentemente alternam com outros róticos", como no Persa, em que "um /r/ vibrante tem um tepe como alofone na posição intervocálica e uma variante vibrante desvozeada na posição final de vocábulo" (p. 158). Ela afirma, ainda, que "do ponto de vista acústico, uma vibrante pode ser vista como uma série de tepes" e que "um tepe é também frequentemente uma variante de uma vibrante, particularmente na posição intervocálica” (p. 166).

A essas observações podem-se acrescentar outros argumentos: (a) em Português os pares mínimos, em contexto de oposição fonológica, têm baixíssima produtividade; (b) no PE, o tepe tem uma maior distribuição do que as demais variantes: ele ocorre em contexto intervocálico (correspondente a $\mathrm{R}$ [+ant]), e predomina, ainda, em ataque complexo e em coda silábica interna e externa; (c) a diferença articulatória entre um tepe e uma vibrante alveolar consiste basicamente, como afirma Lindau, entre uma batida e mais de uma batida nos alvéolos, o que pode não ser saliente para o indivíduo que adotou o Português. Além disso, não se pode esquecer que no Forro, falado em São Tomé, não há róticos (FERRAZ, 1979) e que, por exemplo, no Changana, uma das línguas de Moçambique, só há um rótico, a vibrante alveolar. 
No que concerne aos resultados de Bouchard (2017), que registra a significativa ocorrência de fricativas nos diferentes contextos pré-vocálicos, cabe lembrar algumas de suas observações, no capítulo final da tese, sobre a emergência e o uso dessas variantes (p. 305):

1) [o uso das fricativas] teve um começo repentino; isso foi-me mencionado, em algumas ocasiões, por linguistas que retornaram a São Tomé e Príncipe e notaram a diferença óbvia, e por santomenses que haviam deixado as ilhas e encontrado essa pronúncia rótica quando a elas retornaram; 2) começou entre falantes urbanos e escolarizados; embora o contraste urbano / rural não tenha sido muito discutido nesta tese, considera-se que os santomenses urbanos falam melhor, e eu acho que eles têm uma taxa maior de róticos fricativos do que os santomenses rurais; 3) a fricativa provavelmente soa mais urbana, e aparentemente, "parece legal” - como foi relatado por um linguista em Príncipe, que tinha perguntado aos Principenses [sua opinião] sobre esse novo uso dos róticos.

Como já observaram Brandão et al. (2017, no prelo), o processo de mudança na realização dos róticos não se registra em plenitude nas análises por eles realizadas

mesmo tendo-se passado apenas oito anos da recolha da amostra. Sem dúvida, como já se observou em outras pesquisas sobre o PST (Brandão, 2013, entre outros), fenômenos variáveis nas variedades não europeias do Português são altamente sensíveis a condicionamentos de natureza social. Ao que tudo indica, transformações na sociedade santomense estão se processando de forma acelerada e, em consequência, motivando mudanças linguísticas.

Nesse sentido, os resultados relativos ao PST aqui expostos não só podem servir de base para estudos futuros que mostrem, com maior acuidade, a substituição do tepe e da vibrante alveolar nas posições pré-vocálicas, mas também constituem uma espécie de documento de uma fase em que se estavam apenas esboçando questões de ordem ideológica que viriam a motivar os usuários dessa variedade a encontrar um indicador de sua "santomensidade".

Este estudo, em alguns aspectos, tem caráter preliminar. A continuidade da pesquisa poderá, portanto, determinar ajustes quanto ao que aqui se expôs. Dentre as etapas de trabalho já delineadas encontram-se: (a) ampliar o número de informantes para melhor aferição dos resultados observados, em especial no caso de São Tomé, por Bouchard (2017), que indica a tendência ao uso da fricativa uvular sonora entre indivíduos muito jovens, o que se observou em pouquíssimos dados nas amostras que serviram de base a este estudo e parece mais difundido em onset complexo, contexto aqui não considerado; (b) verificar a hipótese de que indivíduos com nível de escolaridade superior, tanto em São Tomé quanto em Moçambique, poderiam ter consciência do contexto de oposição fonológica, o 
que também poderá ser detectado por meio de uma análise acurada das variantes mais produtivas em determinados itens lexicais; (c) realizar, no âmbito do PM, análises contrapondo falantes de Português L1 e L2.

\section{REFERÊNCIAS}

AgOSTINHO, Ana Lívia dos Santos. Róticos em contexto intervocálico no Português da Ilha do Príncipe: fonologia e educação. Comunicação apresentada ao IX Encontro da ABECS. Brasília, Universidade de Brasília, 28-30 de novembro, 2016.

BOUCHARD, Marie-Eve. Linguistic variation and change in the Portuguese of São Tomé. Doctoral dissertation. New York University, 2017.

BOUCHARD, Marie-Eve. Language ideologies and use of rhotics in the Portuguese of São Tomé. Encontro Anual da ACBLPE. Caderno de Resumos, 18. Praia: Universidade de Cabo Verde, 2016.

BRANDÃO, Silvia Figueiredo. Aspectos da variedade urbana do Português de São Tomé: resultados e metas de pesquisa. In: AGUILERA, Vanderci Andrade; DOIRON, Maranúbia Pereira Barbosa (Org.). Estudos geossociolinguísticos brasileiros e europeus: uma homenagem a Michel Contini. Cascavel-PR: EDUNIOESTE; Londrina-PR: EDUEL, 2016a. p. 67-87.

BRANDÃO, Silvia Figueiredo. A instabilidade dos róticos no Português de São Tomé. Comunicação apresentada ao Encontro Anual da ACBLPE, 2016. Caderno de Resumos. Praia: Universidade de Cabo Verde, 23-25 de junho, 2016b.

BRANDÃO, Silvia Figueiredo. Róticos nos contextos pré e pós vocálico muma variedade africana do Português. Comunicação apresentada ao IX Encontro da ABECS. Brasília, Universidade de Brasília, 28-30 de novembro, 2016c.

BRANDÃO, Silvia Figueiredo; VIEIRA, Silvia Rodrigues. Comunicação apresentada ao VI Encontro do Grupo de Estudos de Linguas em Contato. Salvador: Universidade Federal da Bahia, 07-09 de dezembro, 2015.

BRANDÃO, Silvia Figueiredo. Patterns of agreement within the Noun Phrase, Journal of Portuguese Linguistics, 12(2): 51-100, 2013.

BRANDÃO, Silvia Figueiredo; DE PAULA, Alessandra. Róticos em duas variedades africanas do Português. Comunicação apresentada ao Encontro Anual da ACBLPE, 2017. Estocolmo, Universidade de Estocolmo, 13-15 de junho, 2017a.

BRANDÃO, Silvia Figueiredo; DE PAULA, Alessandra. Róticos no Português falado em Moçambique. Pôster apresentado ao XXXIII Encontro Anual da Associação Portuguesa de Linguística. Évora, Universidade de Évora, 27-29 de setembro, 2017b.

BRANDÃO, Silvia Figueiredo; DE PAULA, Alessandra. Um estudo comparativo preliminar sobre os róticos em duas variedades africanas do português. Comunicação apresentada ao Encontro Intermediário do GT de Sociolinguística da ANPOLL, Porto Alegre, Pontifícia Universidade Católica-RS, 22-24 de novembro, 2017c. 
BRANDÃO, Silvia Figueiredo; PESSANHA, Davi Bretas dos Santos; PONTES, Stefany de Paulo. Róticos na variedade urbana do Português de São Tomé. Papia, 27(2): 191-213, 2017, no prelo.

DIAS, Hildizina (2009) A norma padrão e as suas mudanças linguísticas na língua portuguesa nos meios de comunicação de massas em Moçambique. In: DIAS, Hildizina (Org.). Português moçambicano: estudos e reflexões. Maputo: Imprensa Universitária, 2009. p. 389-420.

EMBE, Cristina. As oclusivas orais no português em falantes nativos emakhuwa. Tese (Licenciatura) - Universidade Pedagógica, 1992.

FERRAZ, Luiz Ivens. The creole of São Tomé. Johannesburg: Witwatersrand University Press, 1976.

GONÇALVES, Perpétua. A gênese do Português de Moçambique. Lisboa: Imprensa Nacional/Casa da Moeda, 2010.

GONÇALVES, Perpétua. O Português em África. In: RAPOSO, Eduardo B. P.; NASCIMENTO, M. F. B.; MOTA, M. A. C. da; SEGURA, Luísa; MENDES, Amália. Gramática do Português. Lisboa: Fundação Calouste Gulbenkian, 2013. v. 1, p. 157-178.

HAGEMEIJER, Tjerk. As línguas de São Tomé e Príncipe. Revista de Crioulos de Base Lexical Portuguesa e Espanhola, Macau, 1(1): 1-27, 2009.

HOMO, Manuel. Supressão e inserção das consoantes nasais em palavras do português por falantes nativos de tsonga: caso de Maputo. Tese (Licenciatura) - Universidade Pedagógica, 2002.

LABOV, William. Sociolinguistic patterns. Philadelphia: University of Pennsylvania Press, 1972.

LABOV, William. Principles of linguistic change: internal factors. Oxford: Blackwell, 1994. v. 1.

LABOV, William. Principles of linguistic change: social factors. Oxford: Blackwell, 2001. v. 2 .

LABOV, William. Some sociolinguistic principles. In: PAULSTON, Christina Bratt; TUCKER, Richard G. (Ed.). Sociolinguistics: the essential readings. Blackwell Publishing, 2003. p. 234-250.

LADEFOGED, Peter. A course in phonetics. New York: Hartcourt Brace Jovanovich, 1975.

LADEFOGED, Peter; MADDIESON, Ian. The sounds of world's languages. Oxford: Blackwell, 1996.

LINDAU, Mona. The story of /r/. In: FROMKIM, Victoria A. (Org.). Phonetic Linguistics: essays in honor of Peter Ladefoged. Orlando: Academic Press, 1985. p. 157-168.

LINDAU, Mona. Vowel features. Language, 54: 541-563, 1978.

MATEUS, Maria Helena Mira; D’ANDRADE, Ernesto. The phonology of portuguese. Oxford: University Press, 2000. 
MAURER, Philippe. L’Angolar: un créole afro-portugais parlé à São Tomé; notes de grammaire, textes, vocabulaires. Hamburg: Helmut Buske Verlag, 1995.

NGUNGA, Armindo; SIMBINI, Madalena Citia. Gramática descritiva da língua changana. 2012. Maputo: Centro de Estudos Africanos (CEA) - UEM: 2012.

SANTOS, Eduardo Ferreira dos. Análise preliminar da palavra prosódica no português vernacular de São Tomé e Príncipe e no português falado em Angola. Papia: Revista Brasileira de Estudos Crioulos e Similares, 22(1): 77-89, 2012.

SILVEIRA, A. C. Ditongos no Português de São Tomé e Príncipe. 2013. 180fls. Dissertação (Mestrado em Filologia e Língua Portuguesa). Faculdade de Filosofia, Letras e Ciências Humanas, Universidade de São Paulo, 2013.

SEIBERT, Gerhard. Crioulização em Cabo Verde e São Tomé e Príncipe: divergências históricas e identitárias. Afro-Ásia, 49: 41-70, 2014.

TIMBANE, Alexandre Antonio; BERLINK, Rosane de Andrade. A norma-padrão europeia e a mudança linguística na escola moçambicana. Gragoatá (32): 207-226, 2012.

VICENTE, Francisco. Consciência fonológica no ensino básico em Moçambique. Tese (Mestrado) Universidade de Lisboa, 2009.

VICENTE, Francisco. Consciência fonológica no ensino básico em Moçambique. In: GONÇALVES, Anabela; DUARTE, Inês; FREITAS, Maria João (Org.). Avaliação da consciência linguística: aspectos fonológicos e sintácticos do Português. Lisboa: Colibri, 2010. p. 69-93.

WEINREICH, Uriel; LABOV, William; HERZOG, Marvin. Empirical foundations for a theory of linguistic change. In: LEHMANN; Winfred P.; MALKIEL, Yakov (Org.). Directions for historical linguistics. Austin: University of Texas Press, 1968. p. 97-195. 